\title{
O lado oculto do mundo da moda
}

\author{
The dark side of the fashion world
}

Silvia R. Freitas', Angélica M. Claudino²

As recentes mortes de modelos ocorridas no Brasil e no exterior por complicações de anorexia nervosa (AN) ecoaram na mídia e no mundo da moda, uma vez que foram globalmente divulgadas e comentadas. Tais fatos tiveram um impacto jamais antes observado, despertando mundialmente a atenção e a preocupação para com o problema dos transtornos alimentares (TA), patologias que, embora já bem reconhecidas em diversos países desenvolvidos, pela primeira vez ganharam tal visibilidade em nosso meio. No debate de jornalistas, modelos e seus agenciadores, estilistas, juristas e, claro, profissionais da saúde e especialistas da área, uma questão sempre pairava no ar: "Seria o mundo fashion o grande vilão da anorexia nervosa?" ou, ainda, "seriam os transtornos alimentares os representantes do lado oculto do mundo da moda?".

Historicamente, sabemos que estados de recusa alimentar e de inanição auto-imposta acham-se descritos nos tempos bíblicos e receberam desde explicações sobrenaturais até concepções de ordem médica, baseadas na investigação científica. À época de sua descrição (1874), não houve referência ao aspecto psicopatológico considerado hoje central na AN, o "medo mórbido de engordar". Contudo, em 1889, Charcot descreveu que uma idée fixe d'obesité estaria por trás dos jejuns de mulheres (Cordás e Claudino, 2002).

A AN acha-se distribuída entre as diferentes culturas, tendo manifestado aumento da incidência em mulheres jovens ao longo do século XX, com possível estabilização nas últimas três décadas (Hoek, 2006). Por sua vez, a bulimia nervosa (BN), com descrição mais recente (1979) e partilhando com a AN o aspecto de preocupação excessiva com o peso e a forma corporal, vem crescendo em incidência tanto em regiões ocidentalizadas quanto naquelas que vivem rápidas mudanças socioeconômicas e culturais (Schmidt, 2003). Estima-se que, pelo menos, 10\% das mulheres jovens apresentam algum TA. Tais quadros levam a grandes prejuízos às saúdes física e psicológica, tendo a AN a mais alta taxa de mortalidade entre as doenças psiquiátricas (5\% por década de doença) (Hoek, 2006).

Outro aspecto relevante diz respeito aos prejuízos sociais e econômicos, ainda muito pouco conhecidos. Considerando-se a faixa etária mais freqüentemente acometida, deparamo-nos com adolescentes que vêem seus projetos de vida adiados, quando não interrompidos, seja pelo TA em si, seja pelas freqüentes complicações clínicas ou comorbidades psiquiátricas prevalentes nessa população. A literatura sugere que os custos sociais e de saúde com os TAs podem ser superiores àqueles de graves doenças psiquiátricas como a esquizofrenia e o transtorno de humor bipolar (Schmidt, 2003).

1 Mestra em Epidemiologia pelo Instituto de Medicina Social (IMS) da Universidade do Estado do Rio de Janeiro (UERJ). Coordenadora do Grupo de Obesidade e Transtornos Alimentares (Gota) do Instituto Estadual de Diabetes e Endocrinologia do Estado do Rio de Janeiro (IEDE-UFRJ).

2 Doutora em Psiquiatria pela Universidade Federal de São Paulo (Unifesp/EPM). Coordenadora do Programa de Orientação e Assistência a Pacientes com Transtornos Alimentares (Proata) do Departamento de Psiquiatria da Unifesp/EPM. 
E quanto à sua etiologia? Qual seria a participação da indústria da moda nos TAs?

Até o momento, a pesquisa etiológica na área nos permite dizer que estamos diante de patologias multifatoriais. Os avanços biotecnológicos nos informam que a genética pode contribuir com aproximadamente $30 \%$ a $80 \%$ do risco de desenvolver tais transtornos, todavia os achados de aumento de incidência desses transtornos nos últimos 40 a 50 anos nos fazem refletir sobre o impacto que as mudanças socioculturais exercem e sua contribuição como fatores desencadeantes e de manutenção (Schmidt, 2003).

É consenso que valores culturais, relacionados ao peso e à forma, podem estimular o início e a manutenção de dietas restritivas para perda de peso, responsáveis em grande parte por desencadear padrões e comportamentos alimentares alterados, como compulsões alimentares e a utilização de métodos inadequados de controle de peso. Sabe-se ainda que certos grupos ocupacionais como bailarinas, modelos e esportistas, que dependem de baixo peso corporal para o sucesso profissional, encontram-se em risco aumentado para o desenvolvimento de TA (Hoek et al., 2003). Desse modo, embora não se possa apontar a indústria da moda como "culpada" pelo desenvolvimento de TA, determinadas exigências nessa área poderiam favorecer a instalação tanto de padrões alterados de comportamento alimentar como de quadros completos de TAs.

Atualmente, vivemos um processo de globalização da beleza, de padronização das formas, muito pouco questionado em nossa sociedade; vivemos mergulhados num "ideal de beleza magra", que carrega múltiplos significados simbólicos, tais como "sucesso", "felicidade" e "poder". Somos bombardeados com imagens de corpos "perfeitos" e confrontados com a redução dos manequins pelas confecções, nos quais precisamos caber como numa fôrma corporal - vale lembrar que modelo tem também o significado de molde, fôrma onde se adapta a matriz e se fundem os tipos (Aurélio, 1999). Ao buscarmos uma identificação com um modelo padronizado e, geralmente, inatingível de beleza, afastamo-nos de nossa própria identidade, resultado de uma bela miscigenação que necessita ser respeitada e valorizada.

Diante dos aspectos anteriormente apresentados e somando-se a movimentos deflagrados na Espanha, na Itália e nos Estados Unidos, alguns serviços brasileiros de pesquisa e assistência a pacientes com TAs se reuniram e se posicionaram, procurando inicialmente contribuir com suas experiências e conhecimento técnico para a elaboração de um documento que norteasse diretrizes para a indústria da moda. Dessa forma, formou-se, em novembro de 2006, a Comissão Técnica de Grupos Especializados no Estudo e Tratamento de Transtornos Alimentares, que vem trabalhando em colaboração com a Associação Brasileira de Psiquiatria (ABP) e com o apoio da Academia de Transtornos Alimentares (Academy for Eating Disorders [AED]), uma organização internacional com excelência em pesquisa, tratamento e prevenção de TAs.

Essas diretrizes representam apenas parte de um amplo projeto de ações que começamos a implementar. O primeiro passo foi a divulgação pela mídia impressa de um "Comunicado à população" (ABP, 2006), vinculado à nota oficial da AED, no qual se alertava para o impacto negativo, sobre as saúdes física e mental, que as exigências dos atuais padrões de beleza podem ter sobre jovens vulneráveis. O passo seguinte será a divulgação dessas diretrizes a empresas e órgãos governamentais competentes.

Como especialistas, consideramos também premente a ampliação de ações de prevenção voltadas para a população geral, compromisso este a ser assumido não apenas por profissionais de saúde, mas por autoridades governamentais e legais, representantes de associações de pais e mestres e de setores ligados à mídia, à indústria da moda e da beleza.

O trabalho com a mídia é de particular importância a fim de estimular a diversificação dos biotipos físicos apresentados e criar mecanismos regulatórios para a veiculação de propagandas que utilizem recursos de manipulação de imagens e que favoreçam a crença na "perfeição estética".

Por fim, é possível que a prevenção secundária, com ações destinadas à detecção e à intervenção precoces mediante a melhoria da capacidade diagnóstica de profissionais de saúde em rede de atenção primária, e a maior disponibilidade de tratamento especializado representem alvo de ações mais realistas na prevenção dos TAs. 


\section{REFERÊNCIAS}

Associação Brasileira de Psiquiatria (ABP). Casos de Transtornos Alimentares Preocupam Entidades. Notícias institucionais [updated 2006 Nov 28, cited 2006 Nov 29]. Available from: <http://www.abpbrasil.org.br/noticias/exibNoticia/?not=368> (link para o comunicado).

Aurélio BAF. Novo Aurélio Século XXI: o dicionário da língua portuguesa. In: Anjos M, Ferreira MB. editores. 3ą ed. Editora Nova Fronteira, p. 1350-1, Rio de Janeiro, 1999.

Cordás TA, Claudino AM. Transtornos alimentares: fundamentos históricos. Rev Bras Psiquiatr, 24 (supl III): 3-6, 2002.

Hoek HW. Incidence, prevalence and mortality of anorexia nervosa and other eating disorders. Curr Opin Psychiatry 19(4): 389-94, 2006

Hoek HW, Hoek D, Katzman MA. Epidemiology and cultural aspects of eating disorders: A review. In: Maj M, Halmi K, López-lbor JJ, Sartorius N, editors. Eating Disorders. WPA Series Evidence and Experience in Psychiatry. Vol. 6 John Wiley \& Sons, p. 91-2, England, 2003.

Schmidt U. Aetiology of eating disorders in the 21st century. New answers to old questions. Eur Child \& Adolesc Psychiatry 12 (suppl 1): 130-7, 2003. 